\title{
Differential sensitivity to paclitaxel-induced apoptosis and growth suppression in paclitaxel-resistant cell lines established from HEC-1 human endometrial adenocarcinoma cells
}

\author{
TETSUJI TANAKA ${ }^{1}$, SAORI TOUJIMA ${ }^{2}$ and JUNKO TANAKA ${ }^{3}$ \\ ${ }^{1}$ Santamaria Hospital, Ibaraki, Osaka 567-0884; ${ }^{2}$ Department of Obstetrics and Gynecology, Wakayama Medical University, \\ Wakayama 641-0012; ${ }^{3}$ Graduate School of Intercultural Studies, Kobe University, Nada-ku, Kobe 657-8501, Japan
}

Received February 28, 2012; Accepted June 15, 2012

DOI: $10.3892 /$ ijo.2012.1600

\begin{abstract}
To investigate acquired paclitaxel (PTX) resistance in cancer cells, we established five monoclonal PTX-resistant cell lines from HEC-1 human endometrial adenocarcinoma cells by means of long-term PTX-exposed cultures and limiting dilution cultures. The established PTX-resistant subclones showed apparent resistance to PTX-induced DNA fragmentation but not to PTX-induced growth suppression. None of the five PTX-resistant subclones showed apparent resistance to other anticancer drugs such as cisplatin, etoposide, 5-fluorouracil, pirarubicin-HCl, 4-hydroxy-cyclophosphamide or mitomycin C. Semiquantitative flow cytometric analysis revealed no apparent differential expression of 17 molecules that were previously reported to regulate apoptosis or drug resistance, between the five PTX-resistant subclones and the parent cells. Karyotyping analysis revealed common changes in chromosomes 4 and 18 in the five PTX-resistant subclones but not in the HEC-1 parent cells. These results indicate that PTX-induced growth suppression is regulated by different mechanisms from those involved in PTX-induced apoptosis. It was concluded that these established PTX-resistant subclones can be useful models in studies related to the prevention or treatment of recurrent cancers after PTX chemotherapy.
\end{abstract}

\section{Introduction}

Recent progress in the development of chemotherapy for advanced cancer has improved long-term overall survival rates. However, acquired drug-resistance during chemotherapy is now a significant clinical problem in advanced cancer patients because it inhibits complete remission. The prognosis of patients

Correspondence to: Dr Tetsuji Tanaka, Santamaria Hospital, 13-15 Shinjo-cho, Ibaraki, Osaka 567-0884, Japan

E-mail: tetanaka@santamaria-med.jp

Key words: paclitaxel, drug-resistance, apoptosis, endometrial adenocarcinoma with recurrent cancers or advanced malignant tumors would be remarkably improved, if the mechanisms involved in the acquisition of anticancer drug-resistance could be clarified and therapies to overcome drug-resistance or restore drug-sensitivity could be developed.

Paclitaxel (PTX) is an antineoplastic compound extracted from the Pacific yew tree, Taxus brevifolia. It binds to tubulin and inhibits the disassembly of microtubules, thereby resulting in the inhibition of cell division. PTX is now widely used to treat patients with various types of cancers such as lung, ovarian, breast, gastric, endometrial and cervical cancers. Combination chemotherapy with PTX and carboplatin is now the first line chemotherapy for ovarian and endometrial cancer patients. Unfortunately, acquired resistance to PTX in cancer patients has become a major clinical problem in cancer chemotherapy.

There have been many studies that have investigated the molecular mechanisms involved in PTX-resistance in cancer cells. Increased $\beta-1$ integrin expression or enhanced cancer cell adhesion to extracellular matrices has been reported to induce PTX-resistance $(1,2)$. Morphological changes in proliferating cancer cells may affect cellular PTX-sensitivity (3). Cancer cells with higher Fas antigen, an apoptosis-inducing cytokine receptor, are more sensitive to PTX than cells with lower Fas expression (4). Stimulation of CD40, a cell survival cytokine receptor, can inhibit PTX-apoptosis (4). Increased expressions of BCL-2 or BCL-XL, which are apoptosis-inhibitory regulators, have been reported to induce PTX-resistance in cancer cells (5). Increased expression of MDR-1, a multi-drug resistance molecule, has been found to be associated with PTX-resistance (6). Chromosome instability may induce PTX-resistance in cancer cells (7). Previous studies on the mechanisms of PTX-resistance have been performed using various types of human cancer cells including ovarian and breast cancer cells. However, until now there has been no study on PTX-resistance involving human endometrial carcinoma cells.

The purpose of our study was to investigate molecular mechanisms that are associated with acquired PTX-resistance and to explore methods for overcoming PTX-resistance using novel PTX-resistant cell lines derived from human endometrial adenocarcinoma cells. As a result, we have found a novel type of PTX-resistance in cancer cells. 


\section{Materials and methods}

Anticancer drugs. All anticancer drugs were kind gifts from pharmaceutical companies. PTX and etoposide (VP16) were provided by Bristol-Myers Squibb Japan Co., Ltd. (Tokyo, Japan). Mitomycin C (MMC) and 5-fluorouracil (5FU) were provided by Kirin-Kyowa-Hakko Co., Ltd. (Tokyo, Japan). Pirarubicin-HCl (THP) was provided by Meiji-Seika Kaisha Ltd. (Osaka, Japan). Cisplatin (CDDP) was provided by NihonKayaku Co.,Ltd.(Tokyo,Japan).4-Hydroxy- cyclophosphamide (4OH-CPM), a major active metabolite of cyclophosphamide, was obtained from Shionogi \& Co., Ltd. (Osaka, Japan).

Cell line and culture. The moderately differentiated human endometrial endometrioid adenocarcinoma cell line, HEC-1 (8), was purchased from the JCRB Cell Bank (Japan Collection of Research Bioresources Cell Bank, Tokyo, Japan). All cells were cultured in OPTI-MEM (Invitrogen Corp., Carlsbad, CA, USA) supplemented with 5\% fetal calf serum (FCS: Equitech Bio Inc., Ingram, TX, USA), $100 \mathrm{U} / \mathrm{ml}$ penicillin (PC), $100 \mu \mathrm{g} / \mathrm{ml}$ streptomycin (SM) and $0.25 \mu \mathrm{g} / \mathrm{ml}$ fungizone (Invitrogen) in 5\% $\mathrm{CO}_{2} / 95 \%$ air at $37^{\circ} \mathrm{C}$.

Establishment of PTX-resistant subclones from HEC-1 cells. To establish PTX-resistant subclones, HEC-1 cells were cultured with various concentrations of PTX for 3-5 weeks, and the surviving cells were collected. This collection procedure after PTX exposure was repeated six times. Finally, five single cell-derived PTX-resistant subclones, designated PTXr3C, PTXr4B, PTXr6F, PTXr7A and PTXr11B, were established using the limiting dilution method. The monoclonality of each PTX-resistant subclone was also confirmed by chromosome analysis (described below). The establishment of these PTX-resistant subclones took 14 months.

Anticancer drug-sensitivity assays. The effects of anticancer drugs on cell growth were assayed as follows. Cells in the $\log$ phase were detached with $0.25 \%$ trypsin $/ 1 \mathrm{mM}$ EDTA (Invitrogen) and cultured overnight in 96 -well plates $\left(5 \times 10^{3} \mathrm{cells} /\right.$ well). On day 2, various concentrations of anticancer drugs were added to the cells. On day 4, the numbers of viable cells were evaluated using a cell proliferation assay kit (Dojin Corp., Tokyo, Japan) and expressed as the percentages of viable cells relative to the mean number of viable untreated cells. All experiments were performed four to seven times. Data are shown as the mean $\pm \mathrm{SD}$, and comparative data were analyzed using Student's t-test $(\mathrm{n}=6)$ and ANOVA.

DNA fragmentation assay. HEC-1 parent cells and PTX-resistant subclones in the $\log$ phase were detached with $0.25 \%$ trypsin/1 mM EDTA and cultured overnight in culture dishes ( $3 \times 10^{6}$ cells/dish) containing OPTI-MEM/5\% FCS/PC/SM. On day 2 , PTX with a final concentration of $2.5 \mu \mathrm{g} / \mathrm{ml}$ was added to the cells after removal of the floating dead cells. On day 4, genomic DNA was extracted from all cells, including the dead ones, using a SepaGene DNA extraction kit (Sankyo-Junyaku Co., Ltd., Tokyo, Japan) and treated with $100 \mu \mathrm{g} / \mathrm{ml}$ of RNase A (Sigma Chemical Co., St. Louis, MO, USA) in TE buffer (10 mM Tris, pH 8.0, $2 \mathrm{mM}$ EDTA) for $90 \mathrm{~min}$ at $37^{\circ} \mathrm{C}$ to remove any contaminating RNA. Next, approximately $20 \mu \mathrm{g}$ of the genomic
DNA isolated from $5 \times 10^{5}$ cells was electrophoresed in a $1.4 \%$ agarose gel at $50 \mathrm{~V}$ for approximately $2 \mathrm{~h}$, stained with $5 \mu \mathrm{g} / \mathrm{ml}$ of ethidium bromide and visualized using UV fluorescence.

Semiquantitative flow cytometric analysis of cell surface antigens. Cells were detached from culture flasks with $3 \mathrm{mM}$ EDTA in phosphate-buffered saline (PBS), and immunostained as follows. The cells $\left(3 \times 10^{5}\right)$ were incubated with an excess of the primary antibody for $20 \mathrm{~min}$ at $4^{\circ} \mathrm{C}$ and then washed twice with wash buffer (PBS containing $2 \%$ fetal calf serum and $0.1 \% \mathrm{NaN}_{3}$ ). Next, the cells were incubated with FITCconjugated goat anti-mouse IgG $(\mathrm{H}+\mathrm{L})$ (Dako Japan, Kyoto, Japan) for $20 \mathrm{~min}$ at $4^{\circ} \mathrm{C}$ and washed twice with wash buffer. Finally, the cells were suspended in $200 \mu \mathrm{l}$ of wash buffer and analyzed using a FACSCalibur ${ }^{\mathrm{TM}}$ (Beckman Coulter Japan, Tokyo, Japan). The following primary antibodies were used: mouse anti-human CD29 monoclonal antibody (clone K20: Immunotech, Hampshire, UK); mouse anti-human CD30 monoclonal antibody (clone HRS-4: Immunotech, Marseille, France); mouse anti-human CD40 monoclonal antibody (clone mAb89: Immunotech); mouse anti-human tumor necrosis factor receptor (TNFR) (CD120a) monoclonal antibody (Genzyme, Cambridge, MA, USA); mouse anti-human Fas (CD95) monoclonal IgG (clone UB2: MBL, Nagoya, Japan); mouse anti-human CD49a monoclonal antibody (clone TS2/7: AbD Serotec Ltd., Oxford, UK); mouse anti-human CD49b monoclonal antibody (clone 31H4: Serotec Ltd.); mouse anti-human CD49c monoclonal antibody (clone 11G5: Cymbus Biotech Ltd., Chandlers Ford, UK); mouse anti-human CD49d monoclonal antibody (clone 44H6: Cymbus Biotech Ltd.); mouse anti-human CD49e monoclonal antibody (clone SAM1: Beckman Coulter Japan); and mouse anti-human CD49f monoclonal antibody (clone 4F10: Cymbus Biotech Ltd.).

Semiquantitative flow cytometric analysis of intracellular molecules and multidrug-resistance-related molecules. Flow cytometric analysis of intracellular molecules and multidrugresistance-related molecules was performed as follows. Cells were detached from culture flasks with $3 \mathrm{mM}$ EDTA in PBS, and then washed with wash buffer (PBS containing 2\% fetal calf serum). The cells were fixed with $4 \%$ paraformaldehyde in $0.1 \mathrm{M} \mathrm{NaH}_{2} \mathrm{PO}_{4}$ (pH 7.4) for $10 \mathrm{~min}$ on ice. After two washes with wash buffer, the cells were treated with $100 \mathrm{mg} / \mathrm{ml}$ digitonin (Sigma Chemical Co.) for $10 \mathrm{~min}$ at room temperature. After another two washes, the cells were treated with normal mouse IgG to block non-specific binding sites for $5 \mathrm{~min}$ at room temperature, followed by incubation with the primary antibody for $30 \mathrm{~min}$ at room temperature and two further washes. Finally, the cells were incubated in FITC-conjugated goat anti-mouse IgG (Gibco BRL, Carlsbad, CA) for $30 \mathrm{~min}$ at room temperature, washed twice and suspended in $200 \mu \mathrm{l}$ of wash buffer for analyses using a FACSCalibur ${ }^{\mathrm{TM}}$ (Beckman Coulter Japan). The following primary antibodies were used: mouse anti-human BAX monoclonal antibody (clone 2D2: AbD Serotec Ltd.); mouse anti-human BCL-2 monoclonal antibody (clone 100: AbD Serotec Ltd.); mouse anti-human BCL-XL monoclonal antibody (clone 2H12: Acris Antibodies Inc., San Diego, CA); mouse antihuman multi-drug resistance protein-1 (MDR-1) monoclonal antibody (clone UIC2: Acris Antibodies Inc.); mouse anti-human MDR-related protein (MRP) monoclonal antibody (clone 

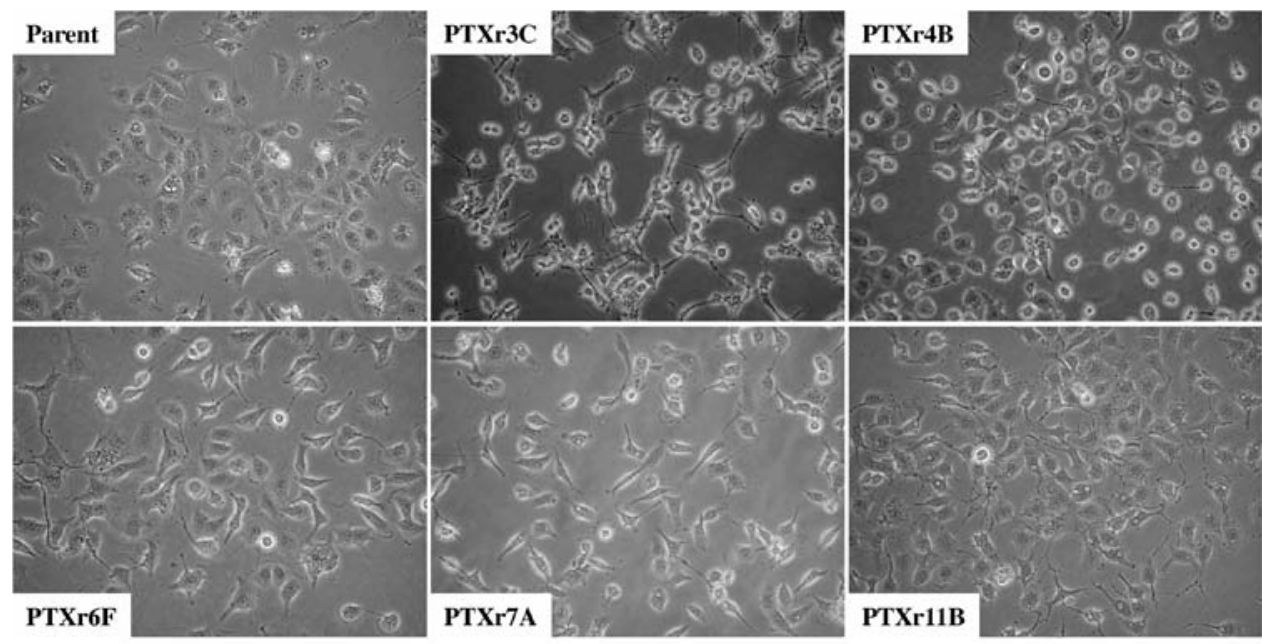

Figure 1. Bright-field microscopic images of cultured HEC-1 parent cells and five PTX-resistant subclones.
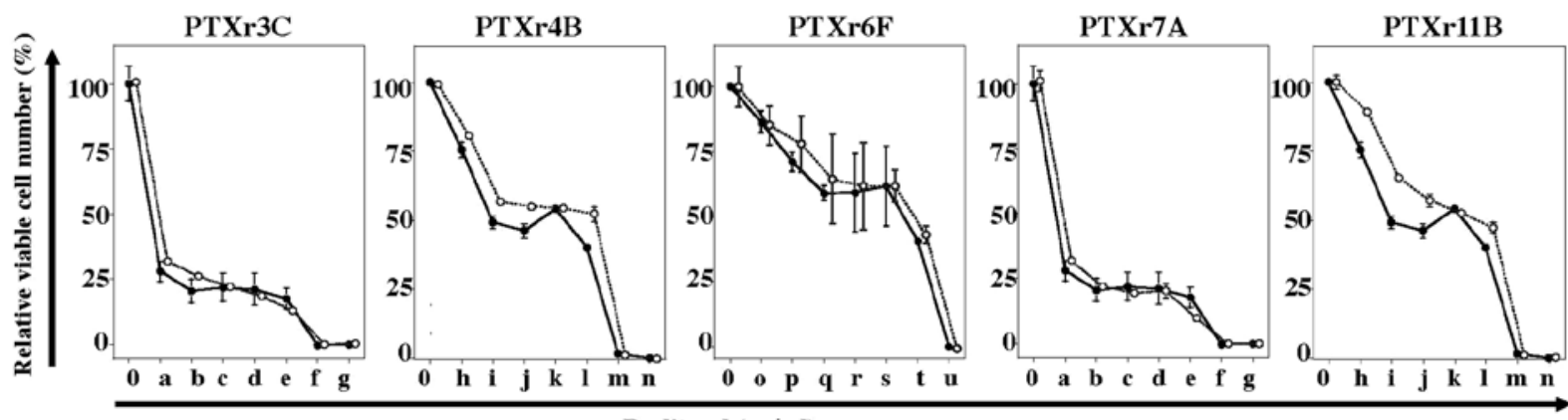

Paclitaxel $(\mu \mathrm{g} / \mathrm{ml})$

Figure 2. PTX-sensitivity assays of the five PTX-resistant subclones. The solid line with closed circles in each plot is the PTX-sensitivity curve for the parent HEC-1 cells. The dotted lines with open circles are the PTX-sensitivity curves for the PTX-resistant subclones. The final concentrations $(\mu \mathrm{g} / \mathrm{ml})$ of PTX indicated as: 0 and $\mathrm{a}-\mathrm{g}$ at the bottom of the figures were $0,0.0064,0.032,0.16,0.8,4,20$ and $100 \mu \mathrm{g} / \mathrm{ml} ; 0$ and $\mathrm{h}-\mathrm{n}$ at the bottom of the figures were $0,0.0015,0.0076,0.0384,0.192,0.96$, 4.8 and $24 \mu \mathrm{g} / \mathrm{ml}$; and 0 and o-u at the bottom of the figure were $0,0.00256,0.0128,0.064,0.32,1.6,8$ and $40 \mu \mathrm{g} / \mathrm{ml}$.

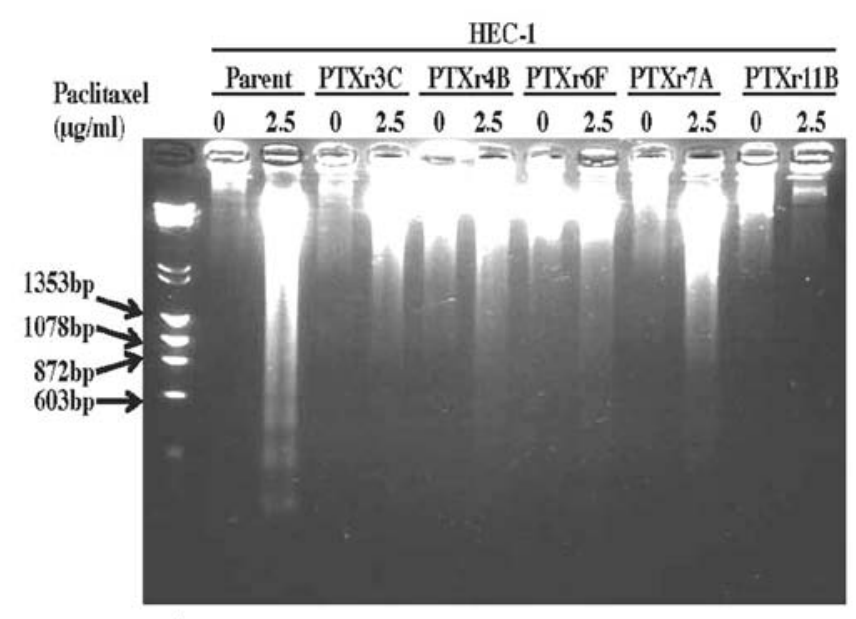

$\uparrow$ hHindIII+Ф/HaeIII

Figure 3. DNA fragmentation assays of the PTX-resistant subclones.

QCLR-1: Merck Millipore, Darmstadt, Germany); and mouse anti-human lung-resistance protein (LRP) monoclonal antibody (clone LRP-56: Merck Millipore).
Karyotyping analysis. Cytogenetic analysis was performed according to previously reported methods $(9,10)$ with the following modifications. Briefly, tumor cell cultures were washed and incubated with $0.1 \%$ (v/v) colcemide (Sigma Chemical Co.) overnight. The cells were then exposed to a hypotonic solution composed of $3 \mathrm{~g} / 1 \mathrm{KCl}, 0.2 \mathrm{~g} / \mathrm{l}$ EGTA and $4.8 \mathrm{~g} / \mathrm{l}$ Hepes. The cells were centrifuged into a pellet and fixed in a methanol solution. G-banding was performed using the method of Yunis (11).

\section{Results}

Establishment of monoclonal PTX-resistant subclones. Five monoclonal PTX-resistant subclones, PTXr3C, PTXr4B, PTXr6F, PTXr7A and PTXr11B, were independently established from HEC-1 cells using long-term PTX-exposure cultures and limiting dilution cultures. Under the microscope, their cellular appearance and adherence to the culture dishes could not be discriminated from those of the parent HEC-1 cells (Fig. 1). Although PTX-sensitivity tests of the PTX-resistant subclones were performed 4-7 times for each subclone, all of the five PTX-resistant subclones showed no significant change in PTX-induced growth inhibition as compared with the HEC-1 parent cells (Fig. 2). However, it 


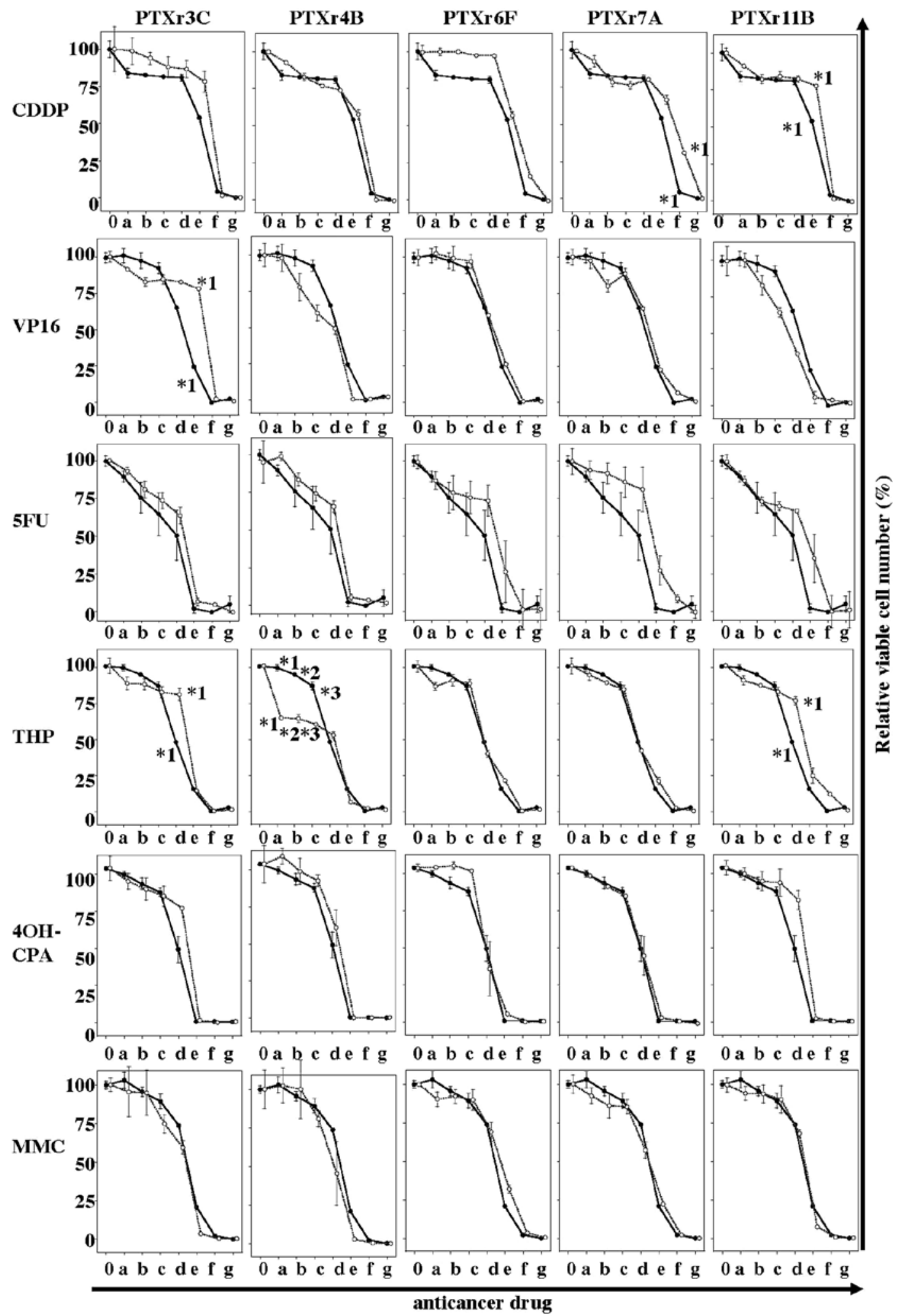

Figure 4. Anticancer drug-sensitivity assays of the five PTX-resistant subclones. The solid line with closed circles in each plot is the drug-sensitivity curve for the parent HEC-1 cells. The dotted lines with open circles are the drug-sensitivity curves for the PTX-resistant subclones. The final concentrations $(\mu \mathrm{g} / \mathrm{ml})$ of each anticancer drug indicated as 0 and a-g at the bottom of the figures were as follows: CDDP, 0, 0.032, 0.16, 0.8, 4, 20, 100 and 500 $\mu \mathrm{g} / \mathrm{ml} ; \mathrm{VP16}, 0,0.256,1.28,6.4,32$, 160,800 and $4,000 \mu \mathrm{g} / \mathrm{ml} ; 5 \mathrm{FU}, 0,0.32,1.6,8,40,200,1,000$ and $5,000 \mu \mathrm{g} / \mathrm{ml} ; \mathrm{THP}, 0,0.001067,0.00533,0.0267,0.133,0.67,3.33$ and $16.670 \mu \mathrm{g} / \mathrm{ml} ; 4 \mathrm{OH}-\mathrm{CPM}$, $0,0.32,1.6,8,40,200,1,000$ and $5,000 \mu \mathrm{g} / \mathrm{ml}$; and MMC, $0,0.128,0.064,0.32,1.6,3.2,40$ and $200 \mu \mathrm{g} / \mathrm{ml} .{ }^{*} 1{ }^{*} 3, \mathrm{p}<0.05$.

was demonstrated using the DNA fragmentation assay that these five PTX-resistant subclones were apparently more resis- tant to PTX-induced DNA fragmentation, or in other words PTX-induced apoptosis, than the parent HEC-1 cells (Fig. 3). 


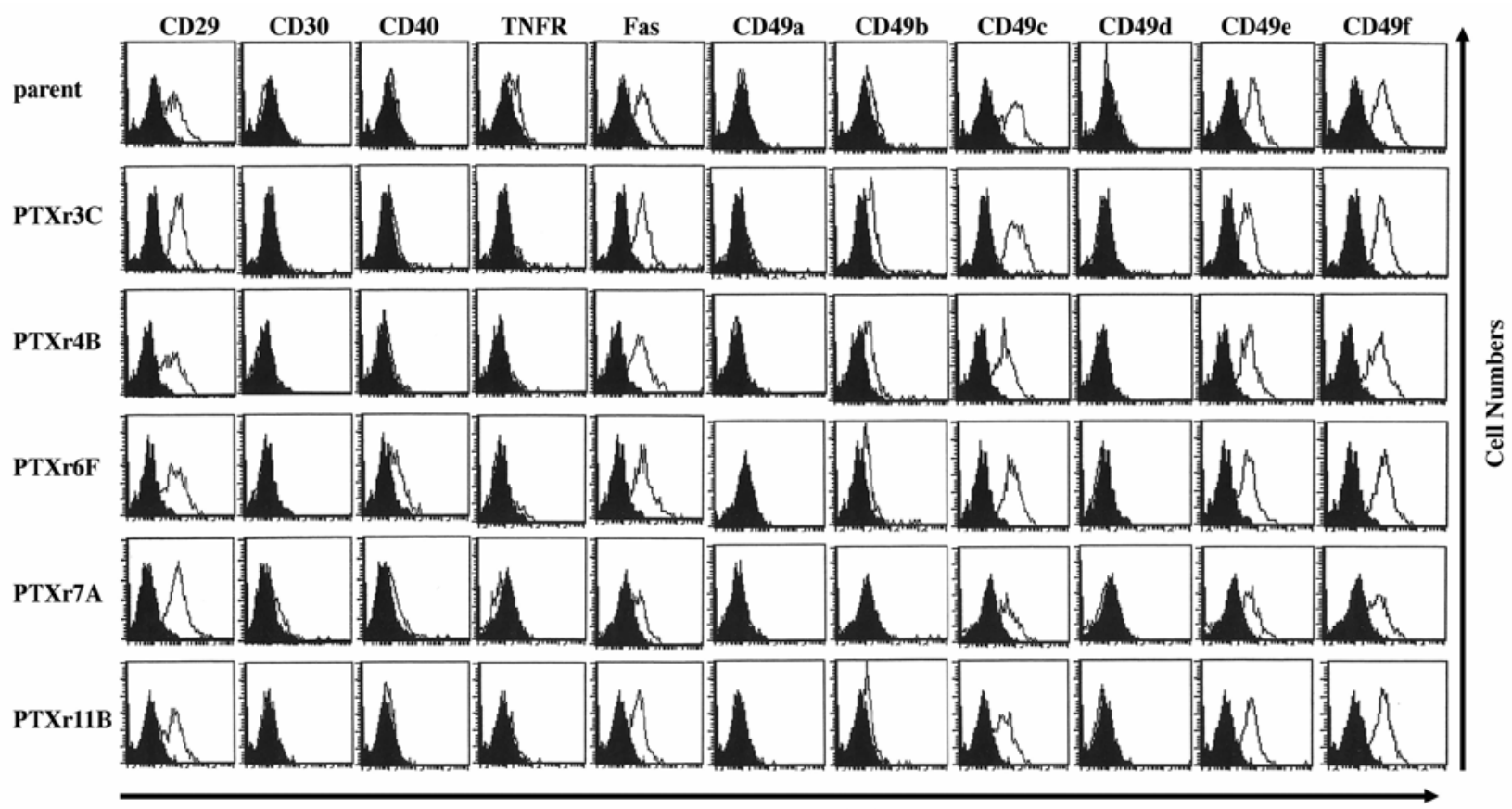

Fluorescence Intensity (log)

Figure 5. Semiquantitative flow cytometric analyses of the expression of cell surface antigen on the PTX-resistant subclones. In the panels, the black histograms show the negative controls, and the white histograms show the positive reactions.

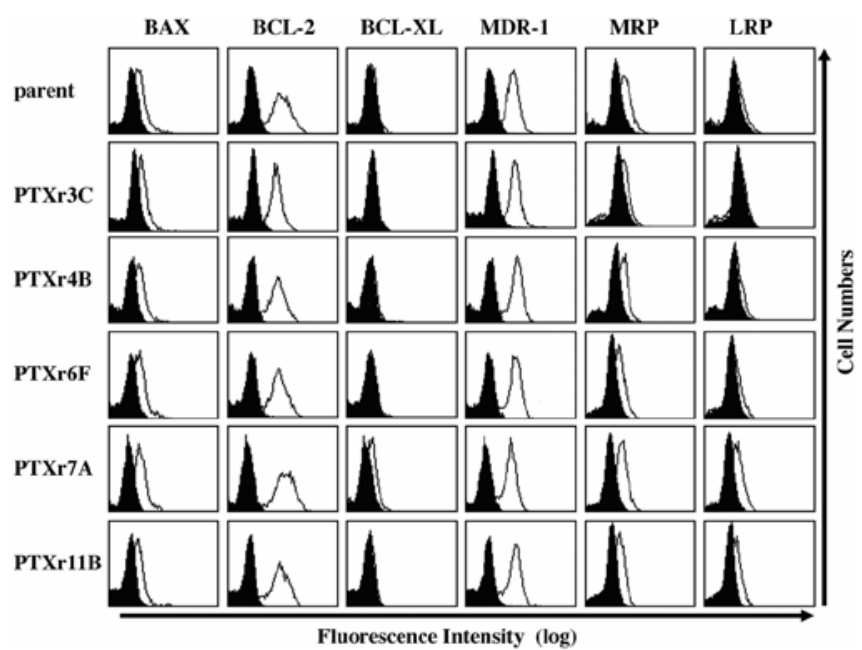

Figure 6. Semiquantitative flow cytometric analyses of the expression of intracellular apoptosis-regulating molecules and multidrug-resistance-related molecules in the PTX-resistant subclones. In the panels, the black histograms show the negative controls and the white histograms show the positive reactions

Anticancer drug-sensitivities of the PTX-resistant subclones. Anticancer drug-sensitivity assays against six anticancer drugs were performed on the PTX-resistant cell lines. As shown in Fig. 4, all the drug-sensitivity curves for the five PTX-resistant subclones showed very similar results to those for the HEC-1 parent cells. There were no PTX-resistant subclones that had moderate or high cross-resistance to any other anticancer drug.

Flow cytometric analysis of cell surface antigen expressions in the PTX-resistant cells. The cell surface antigen expression profiles of the PTX-resistant cell lines were investigated using semi-quantitative flow cytometric analysis. Because all of the PTX-resistant subclones showed resistance to PTX-induced DNA fragmentation, we examined the 11 cell surface antigens that were reported to affect cell apoptosis or cell survival. The flow cytometric data from the parent HEC-1 cells were compared with those from the PTX-resistant cells. However, there were no apparent differences among the flow cytometric profiles of the parent HEC-1 cells and the five PTX-resistant cell lines (Fig. 5)

Semiquantitative flow cytometric analysis of intracellular molecules and multidrug-resistance-related molecules. To investigate the mechanisms of acquired resistance to PTX-induced apoptosis in the PTX-resistant subclones, semiquantitative flow cytometric analysis of three intracellular apoptosis-regulating molecules and three multidrug-resistancerelated molecules was performed. As shown in Fig. 6, no apparent differences in the expression of the six molecules were found among the flow cytometric profiles of the HEC-1 parent cells and the five PTX-resistant cell lines.

Karyotyping analysis of the PTX-resistant cells. Karyotyping analyses of the five in vitro-cultured PTX-resistant subclones were examined (Fig. 7). The karyotype of the parent HEC-1 cell line was $74, \mathrm{XX}, \mathrm{i}(\mathrm{X})(\mathrm{p} 10),+1$, add $(1)(\mathrm{p} 36) \mathrm{x} 2$, der(1)t $(1 ; 12)$ (p22;q11), -2, add(2)(q23)x2, $\operatorname{add}(3)(\mathrm{p} 21),-4,+5,-6, \operatorname{add}(6)(\mathrm{q} 21)$, $+7,-8,+\operatorname{add}(9)(\mathrm{p} 11), \mathrm{i}(9)(\mathrm{q} 10), \operatorname{add}(12)(\mathrm{q} 24), \operatorname{der}(12) \mathrm{t}(12 ; 14)$ (p13; q13), -13, -14, add(15)(p11), +16, +add(17)(p11), add (17) (p11), -18, -19, -20, +21, add(21)(p11)x2, -22, +8mar (Fig. 7A). The karyotype of the PTXr3C cell line was 75, XX, i $(\mathrm{X})(\mathrm{p} 10)$, $\operatorname{add}(1)(\mathrm{p} 36), \operatorname{der}(1) \mathrm{t}(1 ; 12)(\mathrm{p} 22 ; \mathrm{q} 11),-2, \operatorname{add}(2)(\mathrm{q} 23) \times 2, \operatorname{add}(3)$ 
A

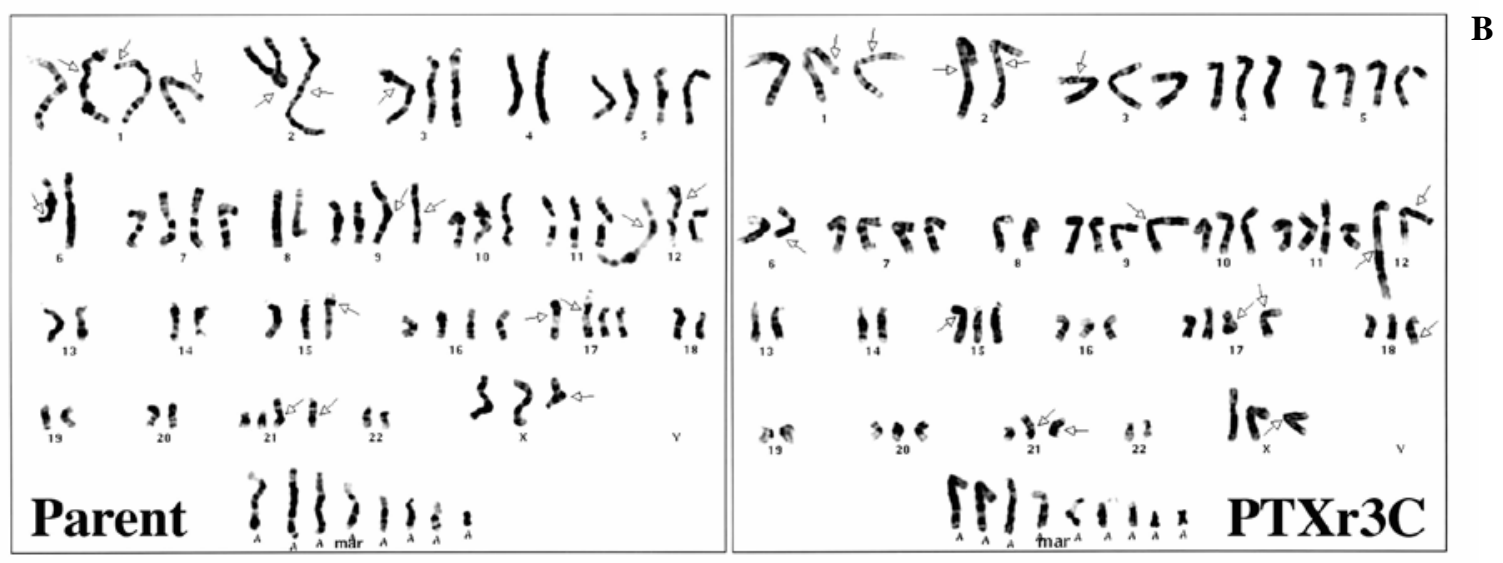

C
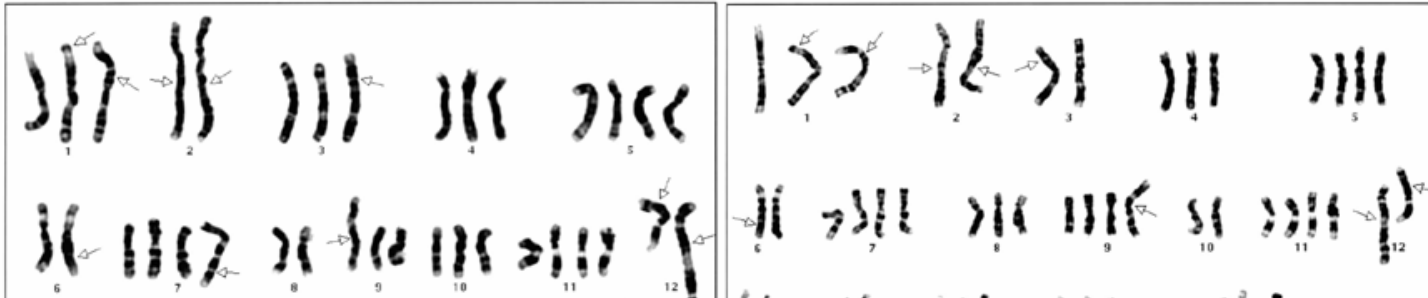

if if $188^{\circ}$ is $24188^{\circ} 38$

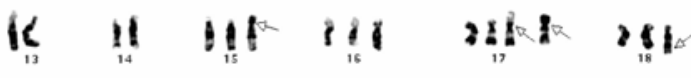

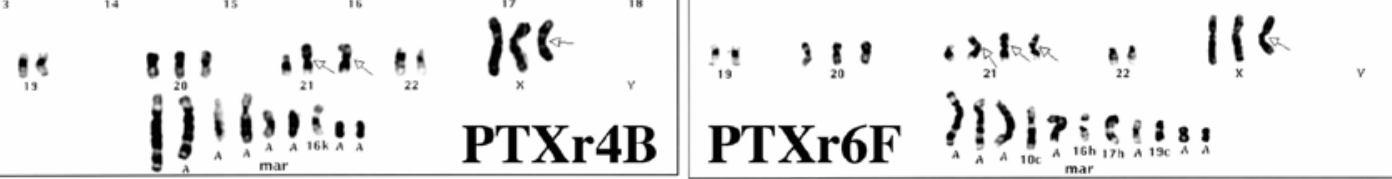

$\mathbf{E}$

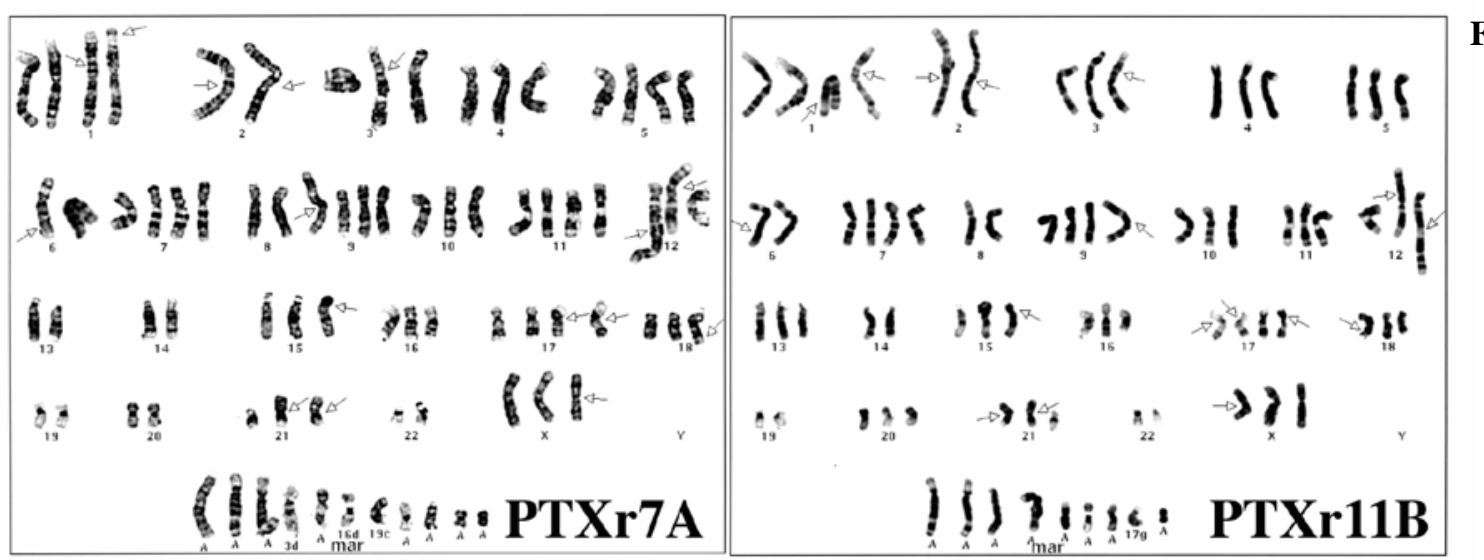

Figure 7. Karyotyping analysis of HEC-1 parent cells and HEC-1-derived PTX-resistant subclones

(p21), $+5,-6, \operatorname{add}(6)(\mathrm{q} 21),+7,-8,+\operatorname{add}(9)(\mathrm{p} 11),+11,-12, \operatorname{add}(12)$ (q24), der(12)t(12;14)(p13;q13), -13, -14, add(15)(p11), $+\operatorname{add}(17)$ (p11), add(17)(p11), add(18)(q23), -19, add(21)(p11)x2, -22, +9 mar (Fig. 7B). The karyotype of the PTXr4B cell line was 75, $\mathrm{XX}, \mathrm{i}(\mathrm{X})(\mathrm{p} 10), \operatorname{add}(1)(\mathrm{p} 36), \operatorname{der}(1) \mathrm{t}(1 ; 12)(\mathrm{p} 22 ; \mathrm{q} 11),-2, \operatorname{add}(2)$ $(\mathrm{q} 23) \times 2, \operatorname{add}(3)(\mathrm{p} 21),+5,-6, \operatorname{add}(6)(\mathrm{q} 23),+\operatorname{add}(7)(\mathrm{q} 32),-8$, add(9)(p11), +11, -12, add(12)(q24), der(12)t(12;14)(p13;q13), $-13,-14, \operatorname{add}(15)(\mathrm{p} 11),+\operatorname{add}(17)(\mathrm{p} 11) \times 2, \operatorname{add}(17)(\mathrm{p} 11), \operatorname{add}(18)$ (q23), -19, add(21)(p11)x2, -22, +9 mar (Fig. 7C). The karyotype of the PTXr6F cell line was 77, XX, i(X)(p10), add(1) (p36), der(1)t(1;12)(p22;q11), -2, add(2)(q23)x2, -3, add(3)(p21), $+5,-6, \operatorname{add}(6)(\mathrm{q} 23),+7,+\operatorname{add}(9)(\mathrm{p} 11),-10,+11,-12, \operatorname{add}(12)(\mathrm{q} 24)$, $\operatorname{der}(12) \mathrm{t}(12 ; 14)(\mathrm{p} 13 ; \mathrm{q} 13),-13,-14, \operatorname{add}(15)(\mathrm{p} 11),+\operatorname{add}(17)(\mathrm{p} 11)$, $\operatorname{add}(17)(\mathrm{p} 11), \operatorname{add}(18)(\mathrm{q} 23),-19,+21, \operatorname{add}(21)(\mathrm{p} 11) \times 3,-22,+11$ mar (Fig. 7D). The karyotype of the PTXr7A cell line was 78, $\mathrm{XX}, \mathrm{i}(\mathrm{X})(\mathrm{p} 10), \operatorname{add}(1)(\mathrm{p} 36), \operatorname{der}(1) \mathrm{t}(1 ; 12)(\mathrm{p} 22 ; \mathrm{q} 11),-2, \operatorname{add}(2)$ (q23)x2, add(3)(p21), +5, -6, add(6)(q23), +7, -8, +add(9)(p11), $+11, \operatorname{add}(12)(\mathrm{q} 24), \operatorname{der}(12) \mathrm{t}(12 ; 14)(\mathrm{p} 13 ; \mathrm{q} 13),-13,-14, \operatorname{add}(15)$ $(\mathrm{p} 11),+\operatorname{add}(17)(\mathrm{p} 11), \operatorname{add}(17)(\mathrm{p} 11), \operatorname{add}(18)(\mathrm{q} 23),-19,-20$, $\operatorname{add}(21)(\mathrm{p} 11) \times 2,-22,+11$ mar (Fig. 7E). The karyotype of the PTXr11B cell line was 76, XX, i(X)(p10), add(1)(p36), der(1) $\mathrm{t}(1 ; 12)(\mathrm{p} 22 ; \mathrm{q} 11),-2, \operatorname{add}(2)(\mathrm{q} 23) \times 2, \operatorname{add}(3)(\mathrm{p} 21),-6, \operatorname{add}(6)(\mathrm{q} 23)$, $+7,-8,+\operatorname{add}(9)(\mathrm{p} 11), \operatorname{add}(12)(\mathrm{q} 24), \operatorname{der}(12) \mathrm{t}(12 ; 14)(\mathrm{p} 13 ; \mathrm{q} 13),-14$, $\operatorname{add}(15)(\mathrm{p} 11),+\operatorname{add}(17)(\mathrm{p} 11), \operatorname{add}(17)(\mathrm{p} 11) \times 2, \operatorname{add}(18)(\mathrm{q} 23),-19$, $\operatorname{add}(21)(\mathrm{p} 11) \times 2,-22,+9 \operatorname{mar}($ Fig. $7 F)$. As a result, common chromosomal abnormalities were found in chromosome 4 and chromosome 18 among the five PTX-resistant subclones, but not in parent HEC-1 cells. 


\section{Discussion}

PTX stabilizes microtubules and, as a result, interferes with the normal breakdown of microtubules during cell division. Therefore, PTX-treated cells have defects in the mitotic spindle assembly, chromosome segregation and cell division. Although PTX is now widely used to treat cancer, acquired or natural PTX-resistance is a major clinical problem in cancer chemotherapy. In order to investigate how to overcome acquired PTX-resistance, we have established five novel monoclonal PTX-resistant subclones from HEC-1, a human endometrioid adenocarcinoma cell line. This is probably the first study in which PTX-resistant cells from human endometrial cancer cells have been established. Most interestingly, all of the established PTX-resistant cell lines showed resistance to PTX-induced DNA fragmentation, but not to PTX-induced growth suppression. The differential resistance exhibited by the PTX-resistant cell lines may be a very rare phenomenon. We could not find any reports concerning anticancer drug-resistant cancer cell lines with such differential resistance as that shown by the PTX-resistant cell lines.

The PTX-resistant cell lines showed no significant changes in sensitivity to drug-induced growth suppression, not only by PTX but also by the six other anticancer drugs used in our study. Using the same experimental methods as those used to establish the present PTX-resistant cell lines, we have previously established many monoclonal anticancer drug-resistant cell lines such as CPA-resistant subclones (12), 5FU-resistant subclones (13), CDDP-resistant subclones (14) and VP16-resistant subclones (15). Almost all of these drug-resistant subclones demonstrated crossresistance to several anticancer drugs including PTX. Both CPA-resistant subclones (12) and 5FU-resistant subclones (13) exhibited $\mathrm{IC}_{50} \mathrm{~s}$ for PTX-sensitivity that were $>125$ times higher than those of their parent cell lines, while VP16-resistant subclones (15) had $\mathrm{IC}_{50}$ s for PTX-sensitivity that were up to five times higher than those of their parent cell lines. The CDDPresistant subclones had $\mathrm{IC}_{50}$ s that were approximately 25 times higher than their parent cell line (14). All of the five PTX-resistant subclones established in the present study showed no apparent cross-resistance to six other anticancer drugs. Most interestingly, the PTX-resistant subclones showed almost the same resistance to 4-OH-CPA and 5FU as the parent HEC-1 cells or very weak cross-resistance to 4-OH-CPA and 5FU. These results suggest that after PTX-chemotherapy PTX-resistant cancer cells may retain high sensitivities to other anticancer drugs. On the other hand, after chemotherapy with CPA, 5FU or CDDP drug-resistant cancer cells might have acquired strong cross-resistance to PTX simultaneously.

All five PTX-resistant subclones showed acquired resistance to PTX-induced DNA fragmentation (PTX-induced apoptosis) but not to PTX-induced growth suppression. These results indicate the possibility that PTX-induced apoptosis is regulated by different intracellular mechanisms from PTX-induced growth suppression. For example, strong crossresistance to PTX-induced growth suppression was found in CPA-resistant subclones derived from the cervical carcinoma cell line ME180 (12) and 5FU-resistant subclones derived from the endometrial carcinoma cell line HHUA (13), while little cross-resistance to PTX-induced growth suppression was found in VP16-resistant ME180 cells (15). Therefore, the differential effects between PTX-induced growth suppression signals and PTX-induced apoptosis signals may depend on the anticancer drugs that were used to establish the drug-resistant cell lines.

The PTX-sensitivity of cancer cells can be regulated by morphological changes in proliferating cancer cells (3) while there was no apparent difference in microscopic findings between the established PTX-resistant cells and parent cells. Morphological changes in proliferating cancer cells are affected by the expression levels and functions of cell adhesion molecules in the cells. In fact there are several reports that increased $\beta 1$-integrin expression or increased cell adhesion to extracellular matrices induced resistance to PTX $(1,2,17)$. Another study demonstrated increased integrin expression in PTX-resistant cells (18). The VP16-resistant subclones, which have weak cross-resistance to PTX, showed decreased expression of CD29, CD49a and CD49f (15). However, the five PTX-resistant subclones established in our study did not show any significant differences in CD29 and CD49a-f expression profiles from those of the parent HEC-1 cells. Because there was no difference in integrin expression and cell proliferation patterns between PTX-resistant cells and the parent cells, the mechanisms of PTX-resistance in the established PTX-resistant subclones may not be caused by the differential cell adhesion ability of the PTX-resistant cells.

Both Fas and TNFR are well-known receptors for apoptosisinducing cytokines. There are several reports that PTX sensitivity can be regulated by apoptosis signals via Fas or TNFR. The high Fas-expressing cells are reported to be more sensitive to PTX (4). PTX treatment can increase production of TNF $\alpha$ (19) and Fas ligand (20) to induce apoptosis. On the other hand, PTX can inhibit TNF $\alpha$ functions in corneal endothelium (21). CD40 is a well-known receptor for the cell survival cytokine, CD40L. Increased CD40 expression has been reported in VP16-resistant cells (15). CD40-stimulation may induce anticancer multidrugresistance in cancer cells (22) and inhibit PTX-induced apoptosis (4). However, in the PTX-resistant subclones in the present study, there was no significant change in the expression of Fas, TNFR and CD40 between PTX-resistant cells and the parent cells.

BCL-2 family products are well-known apoptosisregulators. There are several reports that increased BCL-2 expression and/or BCL-XL expression can induce PTX-resistance $(5,23,24)$. Decreased BAX expression has also been reported to be related to PTX-resistance $(25,26)$. However, in the PTX-resistant subclones in our study there was no significant change in the expression of BCL-2, BCL-XL and BAX between PTX-resistant cells and the parent cells.

MDR-1, MRP and LRP have been identified as multidrugresistance-related molecules. Several studies have found that PTX-resistant cells had increased MDR-1 expression (6) or LRP expression (27), although MRP expression may not have any relationship to PTX-resistance $(5,6)$. In the PTX-resistant subclones in the present study, there was no significant change in the expression of MDR-1, MRP and LRP between PTX-resistant cells and the parent cells.

Because chromosome instability has been reported to affect PTX-resistance (7), we performed karyotype analyses of the established PTX-resistant subclones. All of the five PTX-resistant subclones had common changes in chromosomes 4 and 18 that were different from the parent cells. This finding contrasts with a study involving 5FU-resistant cells, which reported that there 
were no apparent changes in karyotypes relative to the parent cells (13). Chromosomes 4 or 8 might have key genes that affect sensitivity to PTX-induced apoptosis.

Although we have established novel monoclonal PTX-resistant subclones from human endometrial cancer cells, the mechanisms involved in PTX-resistance remain unclear. Most notably, these subclones showed resistance to PTX-induced apoptosis but not to PTX-induced growth suppression. During the acquisition process of PTX-resistance, large differences occurred in the PTX-concentrations required for the induction of growth suppression and apoptosis. In the present study, a much higher dose of PTX was necessary to induce apoptosis in PTX-resistant cells than to induce growth suppression. As shown in Fig. 2, the PTX growth-inhibition curves are stair-like $(12,13,14)$, while those for the other anticancer drugs are sigmoid. Since the docetaxel growth-inhibition curves are also stair-like $(15,28)$, differential sensitivity to drug-induced apoptosis and druginduced growth suppression might be a phenomenon specific to taxane compounds. In conclusion, the novel PTX-resistant subclones from HEC-1 established in our study can be used as experimental models for recurrent cancers occurring after complete remission as a result of PTX-chemotherapy. They may prove to be very useful tools for the investigation of methods to prevent or treat recurrent cancers after PTX-chemotherapy.

\section{References}

1. Chen YX, Wang Y, Fu CC, Diao F, Song LN, Li ZB, Yang R and $\mathrm{Lu} \mathrm{J}$ : Dexamethasone enhances cell resistance to chemotherapy by increasing adhesion to extracellular matrix in human ovarian cancer cells. Endocr Relat Cancer 17: 39-50, 2010.

2. Dong Y, Tan OL, Loessner D, Stephens C, Walpole C, Boyle GM, Parsons PG and Clements JA: Kallikrein-related peptidase 7 promotes multicellular aggregation via the alpha(5) beta(1) integrin pathway and paclitaxel chemoresistance in serous epithelial ovarian carcinoma. Cancer Res 70: 2624-2633, 2010.

3. Loessner D, Stok KS, Lutolf MP, Hutmacher DW, Clements JA and Rizzi SC: Bioengineered 3D platform to explore cell-ECM interactions and drug resistance of epithelial ovarian cancer cells. Biomaterials 31: 8494-8506, 2010.

4. Stumm S, Meyer A, Lindner M, Bastert G, Wallwiener D and Gückel B: Paclitaxel treatment of breast cancer cell lines modulates Fas/Fas ligand expression and induces apoptosis which can be inhibited through the CD40 receptor. Oncology 66: 101-111, 2004

5. Huang Y, Ibrado AM, Reed JC, Bullock G, Ray S, Tang C and Bhalla K: Co-expression of several molecular mechanisms of multidrug resistance and their significance for paclitaxel cytotoxicity in human AML HL-60 cells. Leukemia 11: 253-257, 1997.

6. Kamazawa S, Kigawa J, Kanamori Y, Itamochi H, Sato S, Iba T and Terakawa N: Multidrug resistance gene-1 is a useful predictor of Paclitaxel-based chemotherapy for patients with ovarian cancer. Gynecol Oncol 86: 171-176, 2002.

7. Swanton C, Nicke B, Schuett M, Eklund AC, Ng C, Li Q, Hardcastle T, Lee A, Roy R, East P, Kschischo M, Endesfelder D, Wylie P, Kim SN, Chen JG, Howell M, Ried T, Habermann JK, Auer G, Brenton JD, Szallasi Z and Downward J: Chromosomal instability determines taxane response. Proc Natl Acad Sci USA 106: 8671-8676, 2009.

8. Satyaswaroop PG, Frost A and Gurpide E: Metabolism and effects of progesterone in the human endometrial adenocarcinoma cell line HEC-1. Steroids 35: 21-37, 1980.

9. Gibas Z, Prout GR, Conolly JG, Pontes JE and Sandberg AA: Nonrandom chromosome changes in transitional cell carcinoma of the bladder. Cancer Res 44: 1257-1264, 1984.
10. Yoshida MA, Ohyashiki K, Ochi H, Gibas Z, Pontes JE, Prout GR Jr, Huben R and Sandberg AA: Cytogenetic studies of tumor tissue from patients with nonfamilial renal cell carcinoma. Cancer Res 46: 2139-2147, 1986.

11. Yunis JJ: New chromosome techniques in the study of human neoplasia. Hum Pathol 12: 540-549, 1981.

12. Tanaka T, Bai T, Yukawa K, Utsunomiya T and Umesaki N: Reduced radiosensitivity and increased CD40 expression in cyclophosphamide-resistant subclones established from human cervical squamous cell carcinoma cells. Oncol Rep 14: 941-948, 2005.

13. Tanaka T, Bai T and Toujima S: Establishment and characterization of monoclonal 5-fluorouracil-resistant cell lines derived from human endometrial adenocarcinoma. Int $\mathbf{J}$ Oncol 37: 731-736, 2010.

14. Tanaka T, Toujima S and Umesaki N: Growth-inhibitory signals by activin $\mathrm{A}$ do not affect anticancer drug-sensitivity and acquired multi-drig-resistance in human ovarian endometrioid adenocarcinoma OVK-18 cells. Oncol Rep 11: 667-671, 2004.

15. Tanaka T, Bai T, Yukawa K and Umesaki N: Optimal combination chemotherapy and chemoradiotherapy with etoposide for advanced cervical squamous cancer cells in vitro. Oncol Rep 15: 939-947, 2006.

16. Ohbayashi M, Yasuda M, Kawakami I, Kohyama N, Kobayashi $\mathrm{Y}$ and Yamamoto T: Effect of interleukins response to ECM-induced acquisition of drug resistance in MCF-7 cells. Exp Oncol 30: 276-282, 2008.

17. To K, Fotovati A, Reipas KM, Law JH, Hu K, Wang J, Astanehe A, Davies AH, Lee L, Stratford AL, Raouf A, Johnson P, Berquin IM, Royer HD, Eaves CJ and Dunn SE: Y-box binding protein-1 induces the expression of CD44 and CD49f leading to enhanced self-renewal, mammosphere growth, and drug resistance. Cancer Res 70: 2840-2851, 2010.

18. Işeri OD, Kars MD, Arpaci F and Gündüz U: Gene expression analysis of drug-resistant MCF-7 cells: implications for relation to extracellular matrix proteins. Cancer Chemother Pharmacol 65: 447-55, 2010.

19. Lanni JS, Lowe SW, Licitra EJ, Liu JO and Jacks T: p53-independent apoptosis induced by paclitaxel through an indirect mechanism. Proc Natl Acad Sci USA 94: 9679-83, 1997.

20. Biswas RS, Cha HJ, Hardwick JM and Srivastava RK: Inhibition of drug-induced Fas ligand transcription and apoptosis by Bcl-XL. Mol Cell Biochem 225: 7-20, 2001.

21. Shivanna M and Srinivas SP: Microtubule stabilization opposes the (TNF-alpha)-induced loss in the barrier integrity of corneal endothelium. Exp Eye Res 89: 950-959, 2009.

22. Voorzanger-Rousselot N, Alberti L and Blay JY: CD40L induces multidrug resistance to apoptosis in breast carcinoma and lymphoma cells through caspase independent and dependent pathways. BMC Cancer 18: 75, 2006.

23. Wang MY, Chen PS, Prakash E, Hsu HC, Huang HY, Lin MT, Chang KJ and Kuo ML: Connective tissue growth factor confers drug resistance in breast cancer through concomitant up-regulation of Bcl-xL and cIAP1. Cancer Res 69: 3482-3491, 2009.

24. Luo D, Cheng SC, Xie H and Xie Y: Effects of Bcl-2 and Bcl-XL protein levels on chemoresistance of hepatoblastoma HepG2 cell line. Biochem Cell Biol 78: 119-126, 2000.

25. Janssen K, Pohlmann S, Jänicke RU, Schulze-Osthoff K and Fischer U: Apaf-1 and caspase-9 deficiency prevents apoptosis in a Bax-controlled pathway and promotes clonogenic survival during paclitaxel treatment. Blood 110: 3662-3672, 2007.

26. Strobel T, Kraeft SK, Chen LB and Cannistra SA: BAX expression is associated with enhanced intracellular accumulation of paclitaxel: a novel role for BAX during chemotherapy-induced cell death. Cancer Res 58: 4776-4781, 1998.

27. Kitazono M, Sumizawa T, Takebayashi Y, Chen ZS, Furukawa T, Nagayama S, Tani A, Takao S, Aikou T and Akiyama S: Multidrug resistance and the lung resistance-related protein in human colon carcinoma SW-620 cells. J Natl Cancer Inst 91: 1647-1653, 1999.

28. Tanaka T, Toujima S, Toyoda S, Takeuchi S and Umesaki N: Establishment and characterization of novel human uterine leiomyosarcoma cell lines. Int J Oncol 35: 125-131, 2010. 